\title{
A survey of Information and Communication Technologies as enablers of knowledge capture and retention in three Southern Africa Development Community (SADC) public broadcasting corporations
}

\author{
Peterson Dewah ${ }^{1}$ \\ Dewah@ukzn.ac.za
}

\begin{abstract}
Received: 20 March 2014
Accepted: 21 June 2014

Information and Communication Technologies (ICTs) play an important role in capturing and retaining vital tacit and explicit knowledge which is at risk of loss, yet which an organisation may need for its operations. It is therefore incumbent upon organisations to harness and retain important organisational tacit and explicit knowledge. Between 2009 and 2011 the researcher undertook a survey of ICTs as enablers in knowledge capture and retention in three public broadcasting corporations in the SADC region in order to address the following specific research questions: What is the level of computer literacy among broadcasting staff? At what stage of internet connectivity is each broadcasting corporation and how accessible is the internet to staff members? What ICT infrastructure is available in public broadcasting corporations for knowledge capture and sharing? To what extent do employees have access to various ICTs for knowledge transfer and retention? Which technologies are used to retrieve, share and disseminate knowledge? The study employed the survey method and triangulation of qualitative and quantitative methods of data collection. Data were collected through questionnaires, interviews, observations and content analysis of the three broadcasting corporations' reports and other documents. The major findings were that the three organisations are at different stages of technological advancement, not all offices are computerised, not all employees have access to the internet at work, and telephones are widely used for communication and sharing knowledge. To improve on the use of ICTs for knowledge capture and retention, the organisations need to make available various technologies, computerise all offices, two organisations need proper internet connectivity, and employees should have access to the internet to encourage sharing of knowledge and collaborative activities with other organisations.
\end{abstract}

Keywords: Knowledge, knowledge retention, Information and Communication Technologies, ICT, public broadcasting corporations, SADC.

\section{Introduction}

Knowledge flows out of organisations in various ways, such as through resignations, retirement and death, yet organisations such as public broadcasters are not employing strategies to retain such a vital component of production and service delivery. This study investigated how Information and Communication Technologies (ICTs) are used as tools and enablers of knowledge retention by the three Southern Africa Development Community (SADC) public broadcasting organisations namely: South Africa Broadcasting Corporation (SABC) (South Africa), Department of Broadcasting Services (DBS) (Botswana) and Zimbabwe Broadcasting Corporation (ZBC) (Zimbabwe). ICT is impacting heavily on the way organisations function and plays a vital role in the knowledge society (Rashman et al. 2009). Knowledge retention refers to the capture of critical knowledge and expertise that might be at risk of loss when employees leave an organisation (Kim 2005, Dan 2008, Levy 2011). Appropriate strategies and approaches must therefore be developed to capture employees' expertise and retaining it as organisational knowledge. Knowledgeable, talented and highly qualified professionals were leaving the three public broadcasting organisations resulting in the loss of valuable organisational knowledge (Dewah 2012).

Established in 1936 through an Act of Parliament, the SABC broadcasts in all eleven official South African languages (English, Xhosa, Tshivenda, Sesutu, Ndebele, SiSwati, Tsonga, Tshwane, Sipedi, IsiZulu and Afrikaans) and sometimes in sign language. The SABC creates and broadcasts radio and television content. The Zimbabwe Broadcasting Corporation is a state-run organisation with five radio stations and two television stations: ZTV and Channel 2. ZBC is finding it challenging to achieve its objectives because of knowledge loss from the organisation, redundant equipment, technological obsolescence, and underfunding, among other challenges. The Department of Broadcasting Services in Botswana was formed in April 2003. At the time of this study, Botswana Television (Btv) was the only national television broadcaster. Radio broadcasting began in 1961 and has seen positive developments over time. The division is responsible for Radio Botswana and RB2.

1. Peterson Dewah is a Post-Doctoral Fellow in the Information Studies Programme, University of KwaZulu-Natal. 


\section{Literature Review}

ICTs are electricity-based means of facilitating, seeking, communicating, storing, accessing, manipulating, sending, processing and transmitting information (Marker, McNamara and Wallace 2002: 40). This definition encompasses the full range of ICTs from radio and television to telephones (fixed and mobile), as well as computers and the internet. Knowledge is fundamental for business growth and survival and, in this regard, ICTs play a critical role for the success of any enterprise in a competitive world (McElroy 2002, Alavi \& Leidner 2001). During the transition from an industrialised society to a knowledge-based economy, there has generally been an exponential advancement in ICTs (Johannessen, Olaisen and Olsen 2001). However, the ICTs are limited to the transfer of explicit knowledge and not of tacit knowledge which is also very important in any organisation. For most knowledge management systems, the use of appropriate and user-friendly information technology is fundamental and it is important to ensure that new technology is utilised effectively (Ragsdell 2009). Technology aids knowledge management and knowledge retention. Technology, however, is only an enabler of knowledge building and sharing leading to retention of knowledge, but it does not motivate employees to share their knowledge (Ramirez 2007, Abell and Oxbrow 2001). Technology facilitates the transfer, sharing and retention of knowledge by easing communication channels. ICT is a powerful enabler of development because it improves communication and the exchange of information, thus strengthening and creating new economic and social networks (Mezher 2007) that can facilitate knowledge sharing and retention.

Carlsson (2008: 82) is of the view that, "in acquiring knowledge, a crucial means is the use of information and communication technologies". Despite the fact that new technologies have been part of workplaces everywhere in the world and have rapidly replaced or renewed old technologies, at the same time they bring new challenges (Arntzen and Ndlela 2008). In the three organisations studied (SABC, DBS and ZBC), managers revealed that some old and longserving members were reluctant and unwilling to use new technologies, such as computers to email colleagues for the purposes of sharing, transferring and preserving knowledge. The other challenge is that, when new technology is introduced, employees must be trained to equip themselves with new skills for using the new technologies; consequently there are budgetary implications. Warren (2008) suggests that important issues facing public radio programmes are the expressed needs of program directors to increase the knowledge about new media, how to deal with a broadening of their day-to-day responsibilities, and staying informed about the changes in the new media landscape. The SABC, DBS and ZBC are no exception in this regard. The DBS has had to hire and contract ICT expatriates while ZBC is undercapitalised and as such, training to acquire new skills is affected. Due to technological obsolescence, the three broadcasting organisations have challenges of digitising, scanning and migrating their audio-visual archives to new storage technologies. This study focused on the challenges raised by the intense penetration of information communication technologies in the broadcasting working places and how the broadcasting organisations utilise ICTs as enablers for knowledge sharing, transfer and retention. ICTs facilitate exchanges, knowledge capitalisation and broadcasting. The $\mathrm{SABC}$ has acquired modern equipment that it uses to scan and digitise its knowledge as a way of retaining it for preservation and re-use. The DBS is slowly modernising its equipment in order to capture and retain the knowledge of its experts. The ZBC has funding challenges that makes it difficult to acquire modern equipment for digitising its knowledge products. A Zimbabwe television (ZTV) manager indicated that the ZBC would require US $\$ 50$ million to recapitalise the broadcasting organisation and acquire modern equipment for knowledge capture and retention.

IT-based tools are developed to facilitate communications, for example email, video-conferencing, workflow management systems, and group-decision support systems (Lim 2007: 187). To practise knowledge management most effectively, it is advisable for an organisation to use the latest information technologies to capture, create, store, transfer, share, display, evaluate, maintain and update knowledge (Jain 2009). Technologically, the knowledge network refers to individuals or teams that are connected together by a network of computers. ICTs play a vital role in the retention of knowledge in an organisation by facilitating the transfer, sharing, capturing and storage of knowledge.

The ICT infrastructure and the information systems within the enterprise provide the infrastructure for knowledge networking. The use of ICTs provides new and faster ways of delivering, transferring and retrieving information and knowledge that can improve productivity (Lwoga \& Ngulube 2008, Alavi \& Leidner 2001, Nonaka 1994). ICT tools could be the answer to the problem of acquiring and retaining knowledge by providing access to information to improve broadcasting services and satisfying customers' needs. The SABC is far ahead of the DBS and ZBC in terms of ICT infrastructure developments. ICTs are important as they enhance access to information, make knowledge production and exchange easier and remain an essential knowledge management facilitator (Jain 2009, Kaniki \& Mphahlele 2002).

Turban, McLean and Wetherbe (2004) are of the view that knowledge management systems are developed using three sets of technologies: communication, collaboration and storage. To them, collaboration technologies provide the means to perform group work on common documents synchronously or asynchronously for knowledge contribution. Storage technologies use a database management system to store and manage knowledge. Communication technologies allow users to access required knowledge and communicate with each other via email, the internet, corporate intranets, and other web-based tools.

Various technologies such as email, mailing lists, newsgroups, discussion forums, knowledge web logs and knowledge systems exist to facilitate knowledge creation, sharing and transfer (Mutula \& Mooko 2008). Email exists in various forms, for instance listservs and newsgroups, while mailing lists provide a simple and effective communication mechanism to thousands of subscribers (Mutula \& Mooko 2008). In newsgroups, people can contribute to a discussion on thousands of topics and can be used to build online communities of individuals with common interests.

Computers are used to share knowledge through person-to-person contact and through what Hansen, Nohria and Tierney (1999) refer to as a personalisation strategy. While Hansen, Nohria and Tierney (1999) suggest that the chief 
purpose of computers in some companies or organisations is to help people communicate knowledge, not to store it, Sallies and Jones (2002) agree that computers play a significant role as the main medium for organisational communications and they further point out that computers are good at storing, capturing, structuring and distributing large amounts of information.

Sallies and Jones (2002) suggest that technology aids collaborative processes and the sharing of explicit knowledge; tacit knowledge, too, can be shared through technology, especially virtual environments. They further point out that intranets allow the electronic publication of information, interactions, collaboration and knowledge sharing. The internet gives ready-access to the information on the World Wide Web, facilitates knowledge sharing and encourages learning. ICT tools such as intranets, email, groupware and data warehousing provide a collaborative framework and help capture, storage, dissemination and share knowledge (Newell et al. 2002, Alwert \& Hoffmann 2003).

\section{Research Question}

ICTs play an important role in knowledge management activities such as knowledge capture, retention, sharing, transferring and storage. With the proliferation of various technologies, broadcasting corporations aim to maintain a competitive edge by utilising ICTs to their advantage. While ICTs can facilitate and support various knowledge management activities by providing an enabling role, they can be effectively utilised to capture and retain knowledge in organisations (Toro and Joshi 2013). The key research question is: How do broadcasting organisations utilise ICTs at their disposal to harness, capture and retain knowledge through sharing? The following specific research questions were addressed:

- What is the level of computer literacy among broadcasting staff?

- At what stage of internet connectivity is each broadcasting corporation and how accessible is the internet to staff members?

- What ICT infrastructure is available in public broadcasting corporations for knowledge capturing and sharing?

- To what extent do employees have access to various ICTs for knowledge transfer and retention?

- Which technologies are used to retrieve, share and disseminate knowledge?

\section{Theoretical framework}

The study draws on Kim and Lee's (2006) Organisational Culture, Structure and Information Technology (OCSIT) model. Their theory was based on a study which examined the knowledge sharing capabilities among employees in five public and five private sector organisations in South Korea. They found that IT applications and social networks were central to knowledge sharing activities. They also found that ICT infrastructure supports knowledge sharing activities and assists organisations to get work done, and manages the knowledge assets of the organisation. Besides, the active use of IT or online systems applications gained through career development were found to influence how staff communicated and shared their knowledge.

\section{Methodology}

The study used the survey method and employed the triangulation design for data gathering and analysis. Data were collected by administering a questionnaire to staff and interviews with thirty-seven managers from three public broadcasting organisations in the SADC region. A structured self-administered survey questionnaire was used to purposively sample 165 professionals (including the thirty-seven managers) in the three public broadcasting organisations. The professional staff in the three corporations consisted of journalists, reporters, engineers, radio and television presenters and announcers, librarians, information technology officers, producers, sales and marketing officers, archivists, training officers, human resource officers, events coordinators, finance and accounting officers. Also included in the sample were thirty-seven managers drawn from the following departments: Human Resource, Engineering, Library and Archives, Radio and Television, Finance and Accounts, Administration, Corporate Services, Information and Communication Technology, Sales and Marketing, Programming, Learning and Development, Transport, Procurement, Content Enterprises, Organisational Development, Audiences Services, Licences, Broadcast Information Technology, International Affairs and Public Commercial Services. The researcher conducted thirty-seven face-to-face interviews ranging from forty-five minutes to one hour and fifteen minutes with the managers. Documentary research was also conducted in order to supplement data and fill in gaps. The researcher utilised institutional reports, magazines and brochures to gather more data and fill in gaps.

\section{Results and discussions}

Results are discussed under the headings that follow.

\subsection{Demographic profile of the respondents}

Respondents were asked to provide some personal information such as age, occupation, highest level of education and the section in the organisation within which the respondent was placed. Data obtained from the questionnaires revealed that ages of respondents ranged from less than twenty-five and up to sixty-five years. The majority of the respondents were between the ages 25-35 (seventy-one; 43\%) followed by respondents in the 36-46 age group (fifty-seven; $34.5 \%$ ). Respondents in the age group 47-57 and those less than 25 years of age were ranked third and fourth, with twenty-nine 
$(17.5 \%)$ and six (3.6\%) respectively. The lowest number consisted of two (1.2\%) respondents between the ages of 58-65 years. There were no respondents aged above 65.

In terms of gender, there were more male (eighty-five; 52\%) respondents than females (eighty; $48 \%$ ) in the sample that was studied. The gender disparity in favour of males was even wider at managerial level. Out of the thirty-seven managers who provided qualitative data through interviews, ten (27\%) were females and twenty-seven $(72.9 \%)$ were males.

Level of education and work experience in each organisation were also investigated since research has reported them to be related to organisational knowledge acquisition and retention (De Giovanni 2009, Sveiby 1997). Respondents with higher levels of educational qualifications are presumed to be competent and appreciative of studies that are undertaken in their organisation. They are likely to be aware of the benefits which may accrue if they participate diligently in such studies. Against this backdrop, the present researcher wanted to ascertain the highest level of education attained by each respondent. The results are shown in Figure 1 below:

Figure 1 Highest educational qualification of respondents $(\mathrm{N}=165)$

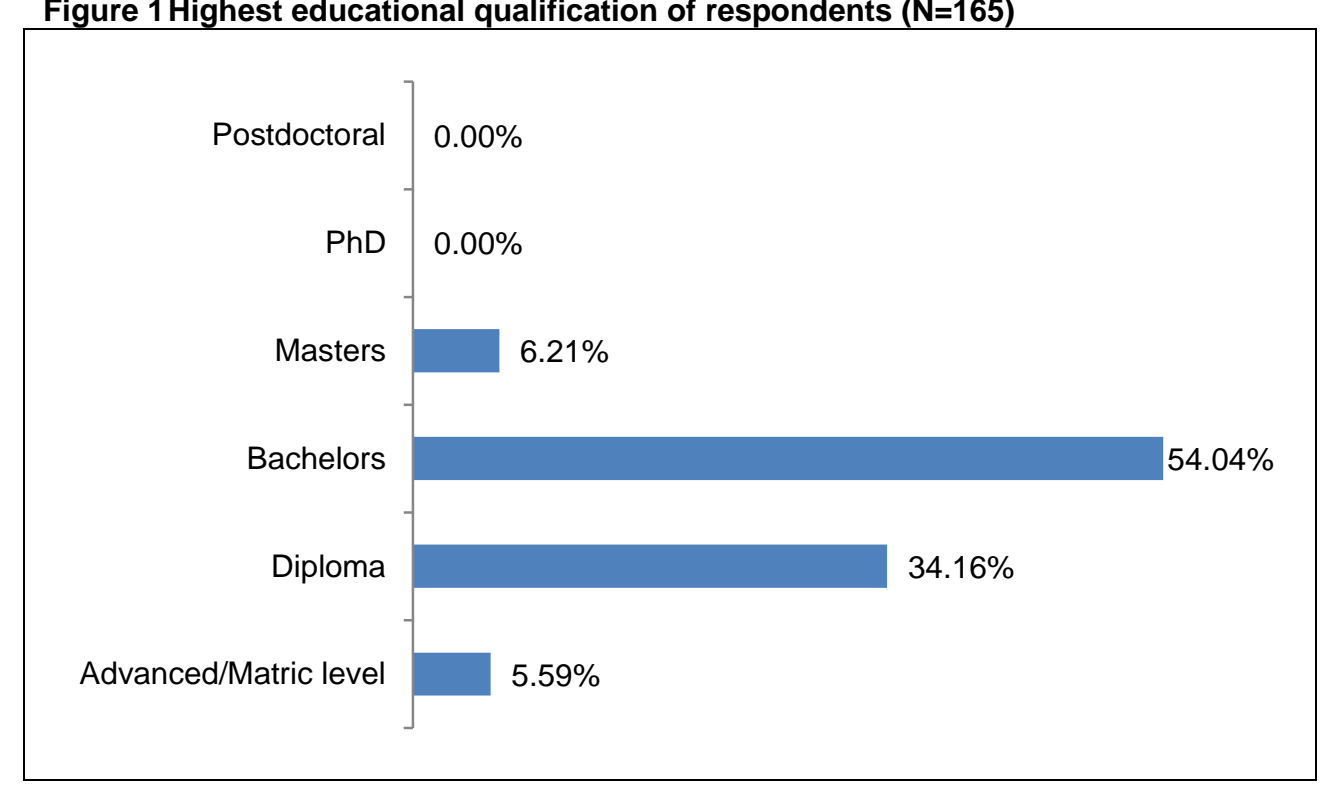

The frequency distribution of respondents revealed that eighty-seven (54.04\%) have Bachelor's degrees, forty-eight $(30 \%)$ are Diploma holders, ten $(6.21 \%)$ have Master's degrees. Matric/Advanced level accounted for $5.59 \%$. Seven $(4.16 \%)$ did not indicate their educational levels. There were no responses in the $\mathrm{PhD}$ and Postdoctoral categories. Interviews revealed that there were no $\mathrm{PhD}$ holders in these organisations which suggest that individuals with such qualifications are more likely to be employed at universities in these countries.

Professionals responding to a questionnaire are likely to provide accurate information regardless of their particular roles in the organisation. The researcher chose managers and their immediate subordinates who were professionals or at least had high school education. It was assumed that managers had particular status and specialised knowledge. Age, gender and level of education can be regarded as predictors of the quality of data that were gathered from the public broadcasting organisations. The profile presented above suggests that the respondents had the working knowledge and experience to give responses and useful opinions on the aspects that were covered in both the main questionnaire and interview guide with regards to their respective broadcasting organisations. The level of education, coupled with the experience attained by individuals, made the respondents assume the role of key informants providing aggregate information or organisational properties rather than personal attitudes and behaviour (De Giovanni 2009: 4).

\subsection{Computer literacy and access to ICTs}

For individual workers to be able to retrieve and share knowledge they must be computer literate. Computer literacy is the ability to utilise computer technology in order to find information and communicate (Laudon \& Laudon 2007). Out of the 156 returned questionnaires, 153 respondents (97.45\%) regarded themselves as computer literate while four $(2.55 \%)$ said they were not computer literate. Five (3.08\%) did not respond to this question. The results are shown in Figure 2. 
Figure 2 Percentage of computer literate respondents $(\mathrm{N}=165)$

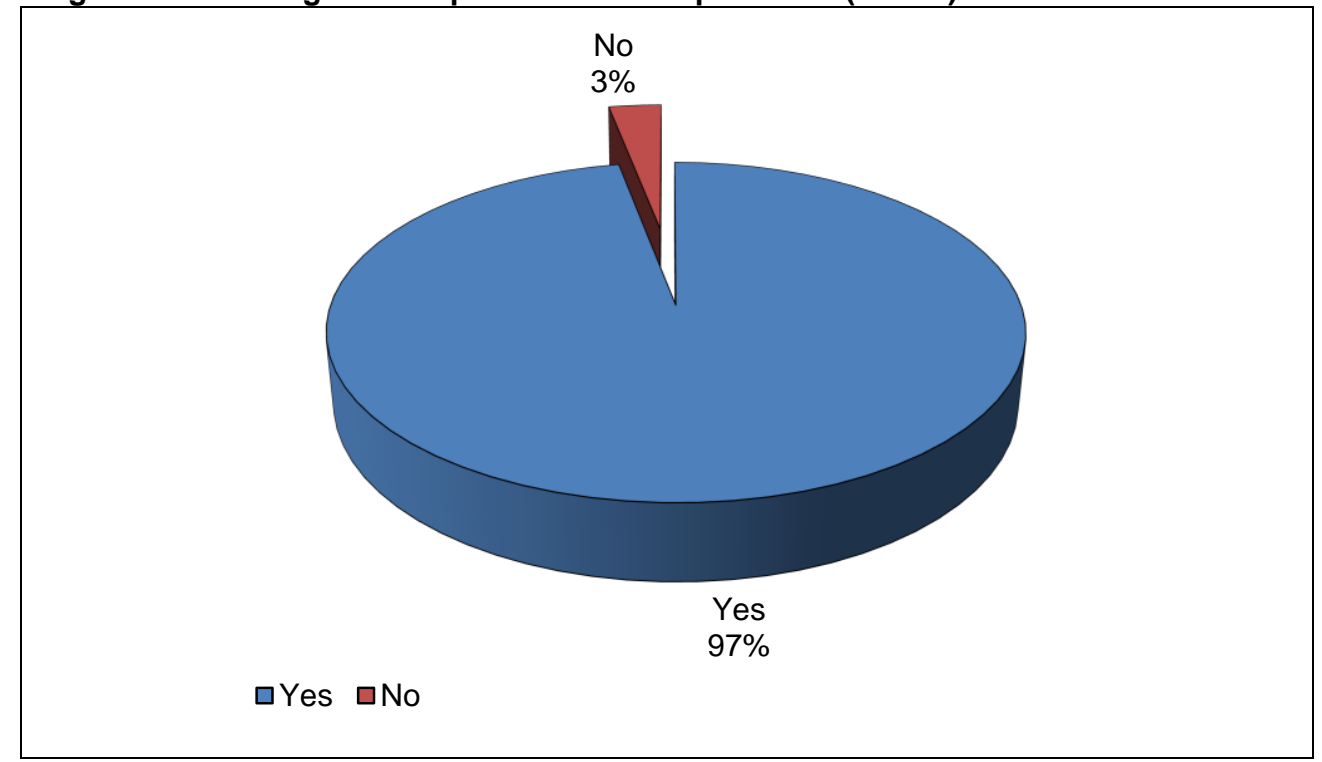

\subsection{Access to ICTs}

Technologies are enablers in knowledge transfer, knowledge sharing and knowledge retention (Carlson 2008, Buckman 2004), therefore respondents were asked which ICTs they had access to in their respective organisations. The results are shown in order of the highest to the lowest in score in Table 1.

Table 1 Access to ICTs

\begin{tabular}{lcc}
\hline \multicolumn{1}{c}{ Tool } & Frequency & Percentage \% \\
\hline Fax & 147 & 90.74 \\
Internet & 136 & 83.95 \\
Intranet/electronic mail & 121 & 74.69 \\
Telephone & 120 & 74.07 \\
Cellphone & 116 & 71.60 \\
Discussion forums & 99 & 61.11 \\
Databases & 90 & 55.55 \\
Knowledge directories & 88 & 54.32 \\
Computers & 82 & 50.61 \\
Virtual conference & 77 & 47.53 \\
Libraries & 68 & 41.97 \\
Websites & 65 & 40.12 \\
Intelligent search engines & 59 & 36.41 \\
Groupware & 58 & 35.80 \\
Electronic bulletin & 56 & 34.56 \\
Wikis & 40 & 24.69 \\
Skype & 33 & 20.37 \\
\hline
\end{tabular}

The majority (147; 90.74\%) of respondents had access to fax, 121 (74.69\%) to intranet/electronic mail, $136(83.95 \%)$ to the internet and $116(71.60 \%)$ to cellphones. One hundred and twenty $(74.07 \%)$ respondents had access to telephones. Wikis $(24.69 \%)$ and Skype $(20.37 \%)$ had the lowest score suggesting that employees did not have access to such ICTs at their workplaces. These percentages show that knowledge, in these organisations, is mostly transferred and retained in the form of documents through faxes, the intranet and the internet, yet Mutula and Mooko's (2008) stance is that electronic mail is by far the most commonly used collaborative tool for communication. Communication can be enhanced and increased by using technology.

However, in a study conducted by Mavodza and Ngulube (2011) the majority (64\%) of the respondents indicated that the knowledge that they needed to perform their job functions was retained in their computers or workstations. This shows 
that, in as much as computers may be utilised to transfer knowledge, they may also be used to store knowledge. The rise of networked computers has made it possible to codify, store and share certain kinds of knowledge more easily and cheaply than ever before (Hansen, Nohria and Tierney 1999).

\subsection{Internet connectivity and access to internet}

Two of the surveyed organisations had no intranet at the time of the study. Interviews with the two respective ICT managers revealed that their sites were under construction. Further probed on the state of organisational technology, the two interviewees (ICT managers) considered their broadcasting organisations as technologically behind others in the region.

If their organisation had internet connectivity, respondents were then asked if they had free access to the internet. The majority, $108(68.79 \%)$, indicated that they had free access to internet but forty-nine $(31.21 \%)$ did not have access to the internet. The results are shown in Figure 3.

Figure 3 Freedom of access to internet within organisation $(\mathrm{N}=165)$

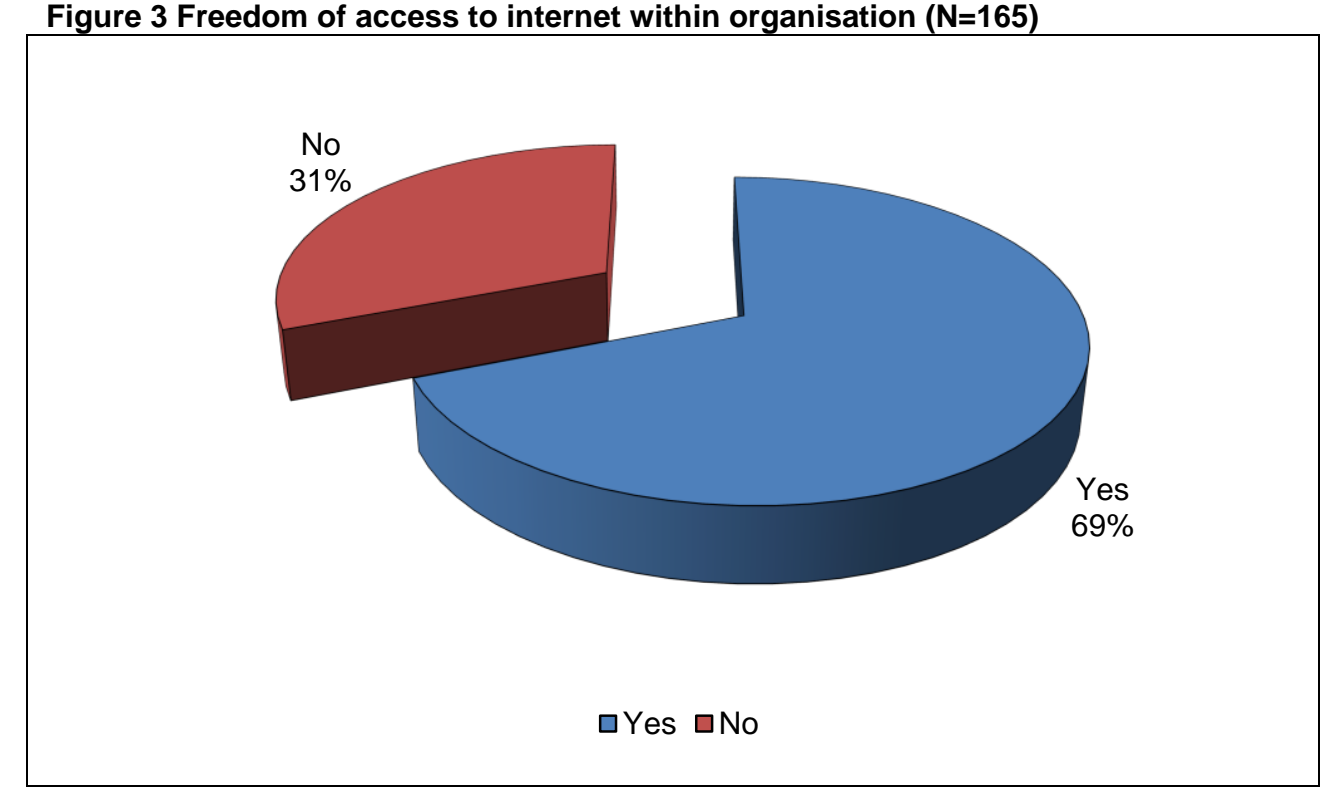

Further probing revealed that those who indicated that they had free access to the internet could access the internet three to five times per day in their respective offices. Those who said they had no access to internet revealed that they had no access to other technologies such as computers in their offices and workmates were reluctant to let them use their office and personal computers. Furthermore, their offices did not have internet connectivity. The majority $(108 ; 68.79 \%)$ of respondents who answered in the affirmative were further asked to indicate how frequently they accessed the internet. The results revealed that fifteen $(12 \%)$ accessed the internet once in a day, one $(0.8 \%)$ twice a day, fifteen $(12 \%)$ two to five times a day, eighty-one $(64.8 \%)$ had unlimited access, while thirteen $(10.4 \%)$ had infrequent access to the internet thus indicated no access or once per day. The results are shown in Figure 4.

Figure 4 Frequency of accessing the internet $(\mathrm{N}=165)$

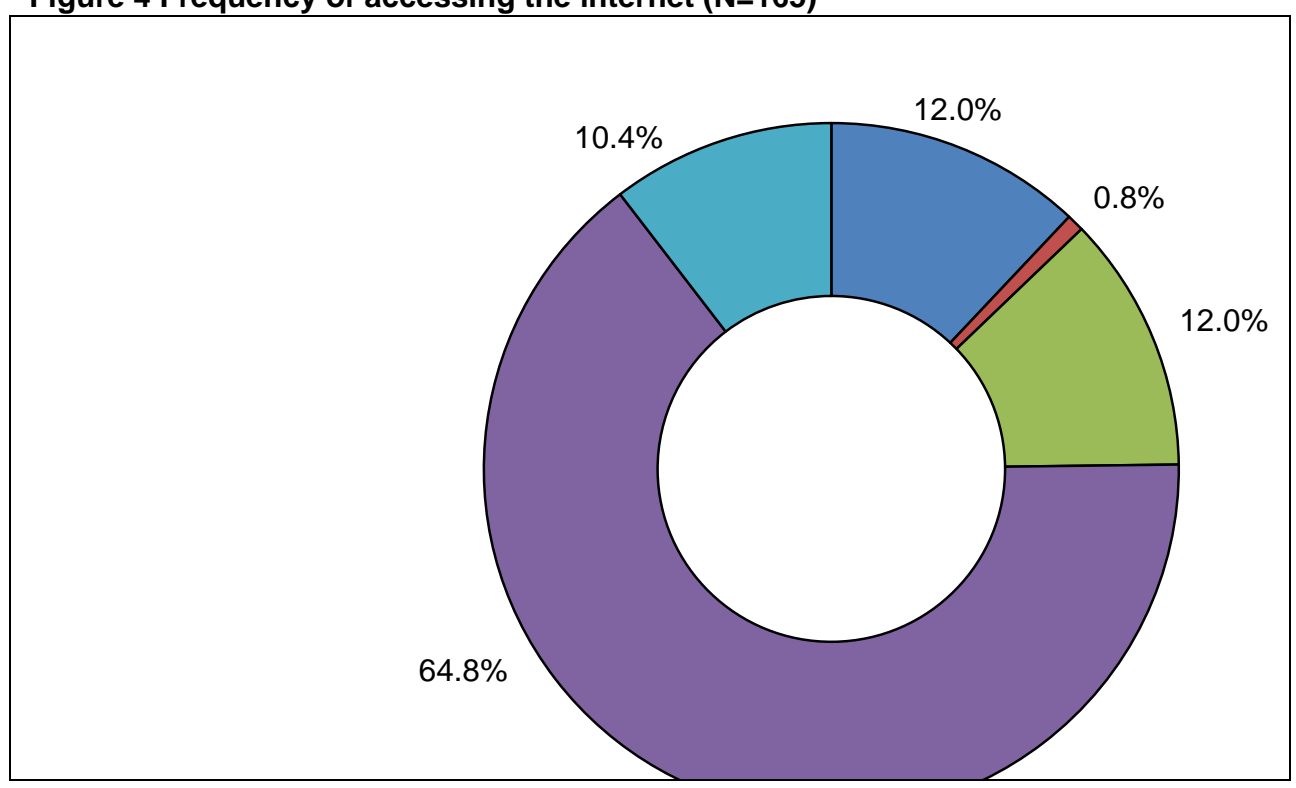


Kim and Lee (2006) found that, with active use of IT or online systems applications, IT applications and social networks were central to knowledge sharing activities. The level of internet penetration has greatly improved in developing countries. The majority (65\%) of respondents indicated that they had unlimited access to the internet. This could be possibly because of internet cafes operating in many parts of towns and cities of the SADC countries as well as access to internet through smartphones. The use of modern information technologies is intended to help an organisation cope with turnover and downsizing by making the expertise of the organisation's human capital widely accessible. Modern information technologies are also built to maintain a well-informed productive workforce, help large organisations provide a consistent level of customer service and help organisations retain the knowledge of departing employees (Turban, McLean and Wetherbe 2004).

\subsection{Technologies used to retrieve, share and disseminate knowledge}

Access to technologies makes it feasible to retrieve, share and disseminate knowledge. Respondents were asked to identify technologies that were accessible to them for the purposes of knowledge retrieval, sharing and dissemination. The results are shown in order of highest to the lowest in Table 2.

Table 2 Technologies used to retrieve, share and disseminate knowledge

\begin{tabular}{lcc}
\hline \multicolumn{1}{c}{ Tool } & Frequency & Percentage \% \\
\hline Telephone & 124 & 76.54 \\
Internet & 110 & 67.90 \\
Computers & 105 & 64.81 \\
Websites & 100 & 61.72 \\
Intranet/electronic mail & 95 & 58.64 \\
Cellphone & 94 & 58.02 \\
Libraries & 86 & 53.08 \\
Fax & 80 & 49.38 \\
Discussion forums & 46 & 29.39 \\
Databases & 37 & 22.83 \\
Electronic bulletin & 31 & 19.13 \\
Intelligent search engines & 23 & 14.19 \\
Virtual conference & 21 & 12.96 \\
Skype & 17 & 10.49 \\
Knowledge directories & 13 & 10.49 \\
Wikis & 13 & 8.02 \\
Groupware & 6 & 3.70 \\
\hline
\end{tabular}

The majority $(124 ; 76.54 \%)$ of respondents used telephone, while $110(67.90 \%)$ used internet, $105(64.81 \%)$ used computers and $95(58.64 \%)$ used intranet/electronic mail. Skype $(8.02 \%)$, knowledge directories $(8.02 \%)$, wikis $(8.02 \%)$ and groupware $(3.7 \%)$ were less used to retrieve, share and disseminate knowledge. These percentages show that in most cases employees use telephone, internet, intranet/electronic mail and cellphones to retrieve, share and disseminate knowledge. While there could be some overlaps between internet and computers, the internet could be accessed through other gadgets such as cellphones.

The study also established that telephones are the most popular tools used to retrieve, share and disseminate knowledge followed by internet, computers, websites, intranet/email and cellphones. Telephones are most popular technologies, possibly because fixed landlines are the most common in organisations and workers use them freely as they transfer costs to the employer. If there were company-sponsored cellphones, employees would utilise them since Parker and Wills (2009) observed that almost $100 \%$ of the population in South Africa lives within range of a mobile communication network.

Companies that primarily adhere to the re-use model will want about $20 \%$ of their knowledge sharing to be person-toperson and therefore encourage the extensive use of email and electronic discussion forums to avoid blind application of documents in situations to which they are ill suited (Hansen, Nohria and Tierney 1999). Participants were requested to identify technologies used in their organisations to capture, retrieve, share, disseminate and retain knowledge. The analysis presented in Table 2 indicated that the majority had access to telephones, the internet, computers, intranet/email and cell phones for knowledge retrieval, capturing and sharing among other tools. This finding is consistent with studies done by Stapplehurst and Ragsdell (2010) and Hansen, Nohria and Tierney (1999), who established that tacit knowledge is shared mainly through face-to-face interaction, over the telephone, by email and even verbally. It is also consistent with studies conducted elsewhere by Fombad (2009) and Stafford and Mearns (2009), where it emerged that telephones, computers, personal networked computers, email, the internet and face-to-face discussions with peers were the most 
important for knowledge sharing and dissemination. Holbeche (2005) observes that most organisations now actively encourage employee use of the internet, intranet, bulletin boards, email and shared databases for knowledge sharing.

This study established that groupware, knowledge directories, wikis, Skype, virtual conferencing, intelligent search engines and electronic bulletins were the least-used technologies in retrieving, sharing and disseminating knowledge. The likely reasons are that the public broadcasting organisations were redirecting resources to other projects and more pressing issues other than information technologies. However, Gottschalk (1999) found that the more information technology is used in an organisation, the greater will be the extent of information technology use for knowledge management. While Gottschalk's study was done in a developed country (Norway) the current study was done in developing countries. Developed countries are more advanced and well-equipped with respect to mass media than developing countries, where there are poorer economic conditions and less technical know-how (Venkataiah 2001).

While intranets are common features in many organisations and well-suited for use as strategic tools in knowledge sharing due to their ability to support the distribution, connectivity and publishing of data and information (Averweg 2008), this study established that only one public broadcasting organisation's intranet was functional. The other two were said to be under construction. One broadcasting organisation cited undercapitalisation and economic woes, while the other pointed out that they were merging with other government departments. The one with a functional intranet had documents posted on the intranet and employees could access them. Information is posted on the intranet on a daily basis. This indicates that IT enables the translation of the organisation's tacit knowledge into explicit knowledge then transfers it to recipients (Stafford and Mearns 2009, Johannessen et al. 2001). The documents available included annual reports, policies, procedure manuals, and such information as job vacancies.

\subsection{Organisational websites}

All the interviewees from the three broadcasting organisations said that their organisations had websites (www.zbc.co.zw, www.sabc.co.za and www.mopipi.bw). Posted on these websites is information such as the organisation's documents, newsletters, monthly reports, content, tenders, stories, both local and international online news, daily bulletins, new products coming to the market, stock market money conversions and advertisements. Studies conducted by Malhan and Gulati (2003) have indicated that intranet and email have such advantages as making savings on travelling costs, more frequent interaction with experts, better coordination, and control of collaborative work.

All three surveyed public broadcasting organisations had ICT departments established to oversee the functions of the technology of their organisation. These days, advances in information technology (IT) have made it easier to acquire, store and disseminate knowledge, and many organisations are employing IT to facilitate the sharing and integration of knowledge (Kankanhali et al. as cited by Averweg 2008). Turban, McLean and Wetherbe (2004) suggest that knowledge management infrastructure such as the internet, intranets, extranets, and data warehouses are built in part from increased pressure to maintain a well-informed, productive workforce. The researcher presumed that a modern broadcaster should likewise be well-equipped technologically. The ICT managers from all three broadcasting organisations confirmed that the IT departments in their respective organisations were the driving force for all the radio and television departments.

\section{Conclusions}

In conclusion, the findings of this study have shown that the majority of the respondents (97\%) were computer literate and therefore were capable of using the computer for knowledge creation, transfer, sharing and retention of explicit knowledge. Nevertheless, of concern was the inaccessibility of the internet to certain staff members. The websites of two broadcasting corporations were not functioning and, as such, this affected the posting of explicit knowledge for both internal and external clients. The respondents had frequent access to certain technologies such as telephones, which they used for knowledge sharing purposes. However, the investigated SADC broadcasting organisations need to be equipped with advanced technology such as those of their counterparts in the developed world, such as the British Broadcasting Corporation (BBC).

\section{Recommendations}

Based on the findings the study therefore made the following recommendations:

- While the study established a high standard of computer literacy $(97.45 \%)$ among staff members, it is recommended that the three public broadcasting corporations should encourage the remainder $(2.55 \%)$ to acquire computer literacy skills.

- The study recommends that all offices of the surveyed organisations should have internet connectivity so that the majority of the workforce will have internet access to enable knowledge acquisition and sharing.

- It is recommended that the public broadcasting organisations ensure that their respective websites are functional to improve internet connectivity, knowledge access, knowledge acquisition and knowledge sharing for retention purposes.

- The study recommends that staff should have access to all organisational ICTs (computers, telephones, cellphones, electronic bulletins, groupware, knowledge directories, and such) in the organisation to facilitate the capture and retention of critical and useful tacit and explicit organisational knowledge in various sections. Given that some of the professionals' offices are not computerised, the study recommends speedy computerisation to 
enable computer networking, access to the internet/intranet, online social networking and establishing online communities of practice. Computers are also used to store and preserve explicit or codified knowledge for future use.

- The study recommends that the organisations facilitate the acquisition of information and communication technologies that enable knowledge management. In this digital age, where almost every job is dependent on ICT facilities, it is a survival necessity to have access to latest technologies to enable employees to work smartly, effectively and efficiently (Jain 2011). The surveyed public broadcasting organisations still lag behind in collaborative and communicative technologies that facilitate retrieval, transfer and sharing of tacit knowledge. Tacit or personalised knowledge is retained in the organisational systems through sharing, collaboration and socialisation.

\section{References}

Abell, A. and Oxbrow, N. 2001. Competing with knowledge: the information professional in the knowledge management age. London: TFPL.

Alavi, M., and Leidner, D.E. 2001. Review: Knowledge Management and Knowledge Management Systems: conceptual foundations and research issues. MIS Quarterly, 25(1): 107-136.

Alwert, K. and Hoffmann, I. 2003. Knowledge Management tools. In Knowledge Management: concepts and best practices. K. Mertins, P. Heisig and J. Vorbeck, Eds. Berlin: Springer-Verlag. 55-76.

Arntzen, A. A. B. and Ndlela, M.N. 2008. The social role in technical architectural knowledge based systems: key of KMS success? Challenges and issues. Proceedings of the $5^{\text {th }}$ International Conference on Intellectual Capital and Knowledge Management. New York: New York Institute of Technology. 45-51.

Averweg, U.R. 2008. Developing an intranet towards knowledge sharing: a practitioner-based inquiry. South African Journal of Information Management, 10(1): 1-13.

Buckman, R.H. 2004. Building a knowledge-driven organization. New York: McGraw-Hill.

Carlsson, S. 2008. Enhancing knowledge acquisition through the use of KMS. Proceedings of the $5^{\text {th }}$ International Conference on Intellectual Capital and Knowledge Management. New York: New York Institute of Technology. 79-86.

Dan, K. 2008. Knowledge retention. [Online]. http://it.toolbox.com/wiki/index.php/Knowledge_Retention (28 February 2011).

De Giovanni, P. 2009. The knowledge manager's role and tasks for supply chain management success. Journal of Knowledge Management Practice, 10(1): 1-15.

Dewah, P. 2012. Knowledge retention strategies in selected Southern Africa public broadcasting corporations. PhD thesis. University of Fort Hare.

Fombad, M. C. 2009. Knowledge Management in law firms in Botswana. PhD thesis. University of Pretoria.

Gottschalk, P. 1999. The use of information technology for knowledge management in law firms. Journal of information, law and technology (JILT), 3(3): 203-211.

Hansen, M., Nohria, N., and Tierney, T. 1999. What's your strategy for managing knowledge? Harvard Business Review, March-April: 106-116.

Holbeche, L. 2005. The high performance organization: creating dynamic stability and sustainable success. Elsevier: Butterworth-Heinemann.

Jain, P. 2009. Knowledge management in e-government. Journal of knowledge management practice, 10(4): 1-10.

Jain, P. 2011. Personal knowledge management: the foundation of organizational knowledge management. South African Journal of Libraries and Information Science, 77(1): 1-14.

Johannessen, J.A., Olaisen, J. and Olsen, B. 2001. Mismanagement of tacit knowledge: the importance of tacit knowledge, the danger of information technology, and what to do about it. International Journal of Information Management, 21(2001): 3-20.

Kaniki, A.M. and Mphahlele, K.M.E., 2002. Indigenous knowledge for the benefit of all: can knowledge management principles be used effectively? South African Journal of Libraries and Information Science, 68(1): 1-15.

Kim, M.P., 2005. Knowledge retention enhances performance-based management. [Online]. http://www.dcma.mil (28 February 2011).

Kim, S., and Lee, H. 2006. The impact of organizational context and Information technology on employee knowledgesharing capabilities. Social Science Journal, 66(3): 370-385.

Laudon, K.C. and Laudon, J.P. 2007. Management information systems: managing the digital firm. $10^{\text {th }}$ ed. New Jersey: Pearson Education.

Levy, M. 2011. Knowledge retention: minimizing organizational business loss. Journal of Knowledge Management, 15 (4): $582-600$.

Lim, S.Y. 2007. The value of knowledge for extended enterprises. In Mapping sustainability knowledge e-networking and the value chain. N. Choucri, D. Mistree, F. Haghseta, T. Mezher, W.R. Baker and C.I. Ortiz, Eds. Dordrecht: Springer. 177-208.

Lwoga, E.T. and Ngulube, P., 2008. Managing indigenous and exogenous knowledge through information and communication technologies for agricultural development and achievement of the UN Millenium Development Goals'. In Libraries and information services towards the attainment of the UN Millenium Development Goals. B. Njobvu and S. Koopman, Eds. Berlin: Walter de Gruyter. 73-88. 
Malhan, I.V. and Gulati, A. 2003. Knowledge management problems of developing countries, with special reference to India. Information Development, 19 (3): 209-213.

Marker, P., McNamara, K. and Wallace, L. 2002. The significance of information and communication technologies for reducing poverty. [Online]. http://www.dfid.gov.uk/pubs/files/ictpoverty.pdf (15 November 2009).

Mavodza, J. and Ngulube, P. 2011. Exploring the use of knowledge management practices in an academic library in a changing information environment. South African Journal of Libraries and Information Science, 77(1): 15-25.

McElroy, M. W. 2002. The new Knowledge Management: complexity, learning and innovation. New York: ButterworthHeinemann.

Mezher, T. 2007. Information and communication technology in the Arab Region. In Mapping sustainability knowledge enetworking and the value chain. N. Choucri, D. Mistree, F. Haghseta, T. Mezher, W.R. Baker and C.I. Ortiz, Eds. Dordrecht: Springer. 101-122.

Mutula, S.M. and Mooko, N.P. 2008. Knowledge Management. In Information and Knowledge Management in the digital age: concepts, technologies and African perspectives. L.O. Aina, S.M. Mutula and M.A. Tiamiyu, Eds. Third World Information Services Limited.

Newell, S., Robertson, M., Scarbrough, H. and Swan, J. 2002. Managing knowledge work. New York: Palgrave.

Nonaka, I. 1994. A dynamic theory of organizational knowledge creation. Organization Science, 5(1): 14-37.

Parker, M. and Wills, G. 2009. Improving the knowledge exchange landscape in the Cape Flats, a developing community in South Africa. [Online]. www.sajim.co.za/peer162.11nr3.asp?print=1 (11 March 2010).

Ragsdell, G. 2009. Inhibitors and enhancers to knowledge sharing: lessons from the voluntary sector. Journal of Knowledge Management Practice, 10(1): 1-9.

Ramirez, A. 2007.To blog or not to blog: understanding and overcoming the challenge of knowledge sharing. Journal of knowledge Management Practice, 8(1): 1-12.

Rashman, L., Withers, E., and Hartley, J. 2009. Organizational learning and knowledge in public service organizations: a systematic review of the literature. International Journal of Management reviews, 11(4): 463-494.

Sallies, E. and Jones, G. 2002. Knowledge management in education: enhancing learning and education. Stylus Publishing Inc.

Stafford, C. and Mearns, M. A. 2009. What happens when organizations embrace social networking? Knowledge sharing at a multinational business solutions corporation. [Online]. www.sajim.co.za/peer162.11nr3.asp?print=1 (11 March 2010).

Stapplehurst, J. and Ragsdell, G. 2010. Knowledge sharing in SMEs: a comparison of two case study organizations. Journal of Knowledge Management Practice, 11(1): 1-16.

Sveiby, K. 1997. The new organizational wealth: managing and measuring knowledge-based assets. San Francisco: Beret-Koehler Publishers.

Toro, U. and Joshi, M. J. 2013. A review of literature on Knowledge Management using ICT in Higher Education. International Journal of Computer Technology and Applications, 4(1): 62-67.

Turban, E., McLean, E., and Wetherbe, J. 2004. Information technology for management: transforming organizations in the digital economy. 6th ed. New York: John Wiley \& Sons.

Venkataiah, S. Ed. 2001. Broadcasting Education. New Delhi: Anmol Publications.

Warren, B.M. 2008. Introducing and implementing a new media Knowledge Management plan for public radio program directors. Master's thesis. University of Pennsylvania. 